\title{
19. A PALEOMAGNETIC EVALUATION OF THE AGE OF THE DOLOMITE FROM SITE 536, LEG 77, SOUTHEASTERN GULF OF MEXICO'
}

\author{
Margaret M. Testarmata, Institute for Geophysics, The University of Texas at Austin, Austin, Texas \\ and \\ Wulf A. Gose, Department of Geological Sciences and Institute for Geophysics, University of Texas at Austin, \\ Austin, Texas
}

\begin{abstract}
Site 536 terminated in a shallow-water dolomite of unknown age. Paleomagnetic measurements combined with strontium isotope analyses suggest that the dolomite was deposited in the Middle Jurassic to Early Cretaceous time interval. However, the assumptions required to reach this determination make these results less than conclusive.
\end{abstract}

\section{INTRODUCTION}

Site 536 bottomed in a shallow-water dolomite of unknown age. Stylolites and a fabric of tight interlocking crystals suggest that the dolomite had been under considerably higher overburden than the present overlying Aptian-Albian talus deposits and thus is probably much older. Multichannel seismic data suggest that this dolomite may represent the upper part of a thick sedimentary section that underlies the southeastern Gulf of Mexico. A good age determination of the dolomite is, therefore, very important for understanding the early geologic evolution of the Gulf of Mexico (Schlager et al., this volume). This paleomagnetic study was undertaken with the objective of providing age constraints. These results are combined with additional age estimates obtained from ${ }^{87} \mathrm{Sr} /{ }^{86} \mathrm{Sr}$ analyses by the Mobil Field Research Laboratory.

\section{PROCEDURE}

Nineteen samples were minicored from $11 \mathrm{~m}$ of recovered dolomite, representing $23 \mathrm{~m}$ stratigraphically. The vertically oriented 1 -in. cylindrical samples were evenly distributed along the core in such a way that dolomites of various colors and textures were sampled. Only pieces that were of sufficient length to preclude any inversion in the core barrel were sampled. Two of the minicores came from the same rock segment and were therefore oriented relative to each other in terms of declination as well as inclination.

Laboratory analysis was conducted in the Galveston Laboratory of the University of Texas Institute for Geophysics using a cryogenic magnetometer. Prior to and during the experimental procedure, samples were kept in a magnetically shielded room whose ambient field was approximately 100 gammas. Fields in the magnetometer and demagnetizing equipment were less than five gammas.

The intensity of the natural remanent magnetization (NRM) ranged narrowly around an average value of $2.6 \times 10^{-7} \mathrm{emu} / \mathrm{cm}^{3}$ (Fig. 1). After all samples had been demagnetized by alternating fields (AF) of 200 oersteds (Oe), the intensities averaged $45 \%$ of the NRM, but covered a broad range (Fig. 1). Samples were than divided into subgroups for further demagnetization. Eight samples were thermally demagnetized at $220^{\circ} \mathrm{C}$ and then $260^{\circ} \mathrm{C}$. Two samples which had little of their magnetization remaining were demagnetized at 300 and 400 Oe. The remaining nine samples were AF demagnetized at $300,400,600,800$, and $1000 \mathrm{Oe}$ and then heated to $220^{\circ} \mathrm{C}$.

\footnotetext{
${ }^{1}$ Buffler, R. T., Schlager, W., et al., Init. Repts. DSDP, 77: Washington (U.S. Govt
} Printing Office).

\section{RESULTS}

Although there were some individual variations, most samples behaved in the same general manner, as best illustrated by orthogonal vector diagrams (Fig. 2). A soft component was erased by demagnetization to 25 to 50 Oe. However, in many cases it was not distinct from the main component which was stable to 200 or 300 Oe. Samples that were demagnetized above 200 Oe tended to hold steady in both direction and intensity from 300 or 400 to 1000 Oe. Upon heating, almost all samples experienced a dramatic decrease in intensity, usually to less than $5 \%$ of the NRM (Fig. 3), and a change in direction. Only three samples revealed a stable component after heating, with intensities equal to $22-40 \%$ of the NRM (Fig. 4). In all three cases, this component has negative inclinations, ranging from -18 to $-44^{\circ}$.

The soft component eliminated at $25 \mathrm{Oe}$ is clearly not representative of the original magnetization. The two main components are the vector erased from 25 to 300 Oe (Component 1) and the magnetization stable at higher demagnetization fields or isolated by thermal demagnetization (Component 2). Table 1 lists both components for all samples.

Component 1 has a wide range of inclinations with only one negative value. Its mean absolute inclination is $40.3^{\circ}$ with a standard deviation of $19.8^{\circ}$. The concentration of inclinations near the present site value of $56^{\circ}$ is conspicuous (Fig. 5A). The two samples oriented relative to each other (Samples 536-23-3, $133 \mathrm{~cm}$ and 536$23-3,143 \mathrm{~cm}$ ) differ by $48^{\circ}$ in inclination and $122^{\circ}$ in declination. Component 2 has a tighter distribution (Fig. 5B) with a mean absolute inclination of $29.1^{\circ} \pm 13.8^{\circ}$, clearly displaced from the inclination at the site today. The two samples with relative orientation are consistent, varying only $4^{\circ}$ in inclination and $21^{\circ}$ in declination. It thus seems reasonable to identify Component 2 as the primary magnetization.

\section{${ }^{87} \mathrm{Sr} /{ }^{86} \mathrm{Sr}$ ANALYSIS}

The ratio of ${ }^{87} \mathrm{Sr} /{ }^{86} \mathrm{Sr}$ of four dolomite samples was measured by the Mobil Field Research Laboratory. The same research group has determined the ${ }^{87} \mathrm{Sr} /{ }^{86} \mathrm{Sr}$ varia- 


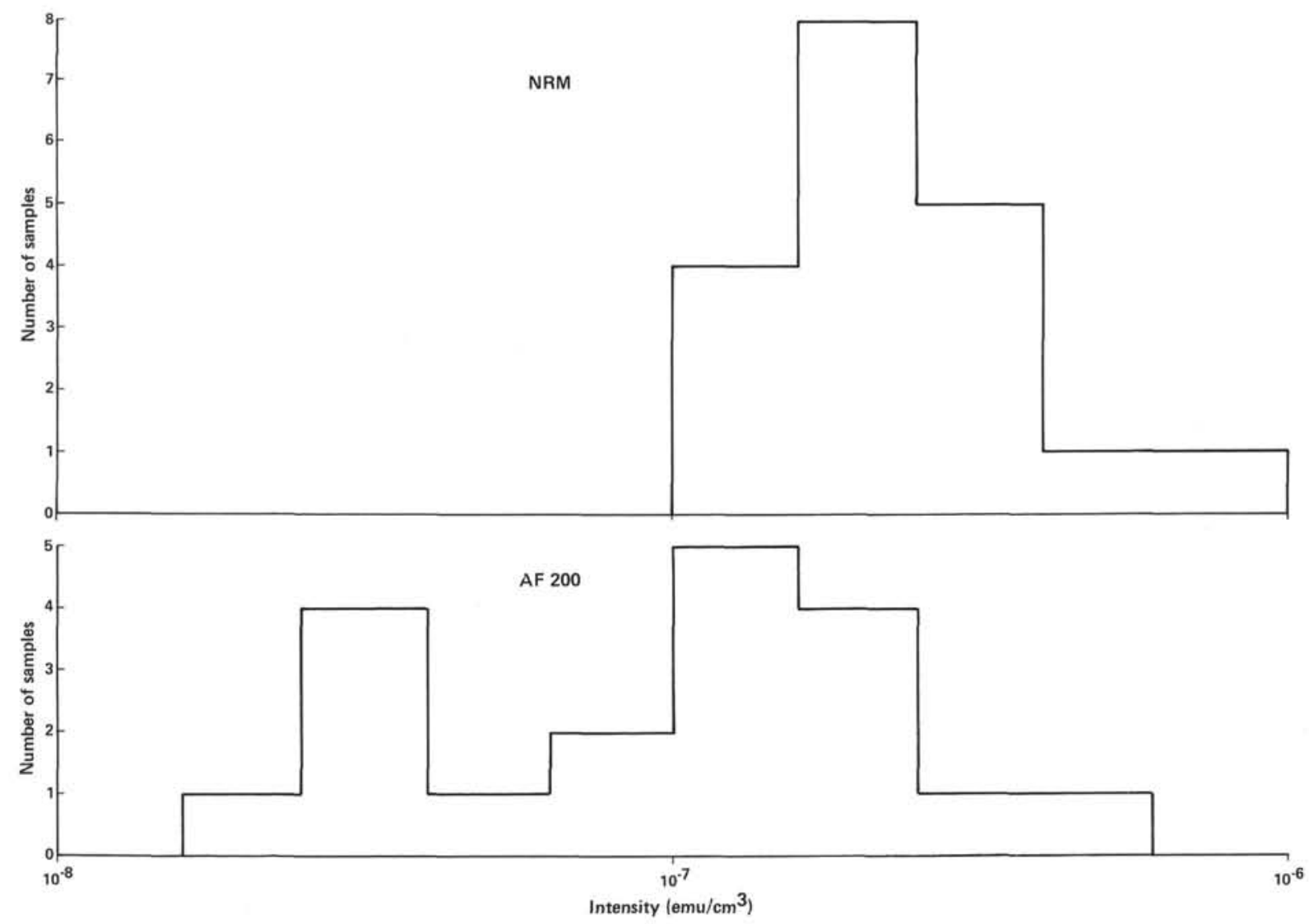

Figure 1. Distribution of the natural remanent magnetization (NRM) intensities and intensities after demagnetization to 200 Oe for the 19 samples from the Site 536 dolomite.

tion of seawater for the Phanerozoic (Burke et al., 1982). If we can assume that the strontium in the dolomite was incorporated from seawater at the time of deposition and has not been affected subsequently, then the age of the dolomite can be inferred by comparison with the reference curve. Verification of this assumption requires a detailed geological analysis, which is beyond the scope of this investigation.

The strontium values are listed in Table 2 and were obtained by comparison with standard $\mathrm{SrCO}_{3}$ (NBS SRM 987), for which a value of 0.71014 has been assumed. Figure 6 shows the strontium ratio reference curve and the absolute range of the dolomite values. Two time windows are indicated, suggesting either a Permian age or a Middle Jurassic through Late Cretaceous age. The talus overlying the dolomite restricts the younger time window to pre-Aptian (120 Ma).

\section{DISCUSSION}

The objective of this paleomagnetic study is to define which of these two time windows represents the dolomite's age. The two pertinent paleomagnetic parameters are inclination and polarity. The expected inclinations for Site 536 can be calculated using the North American polar wander path, if one assumes that the site was in its present position relative to North America. A change of a few degrees, such as might have been caused by crustal stretching, will not change the values significantly. The expected inclinations for Site 536 were calculated using
Irving's (1979) compilation for the Paleozoic and Harrison and Lindh's (1982) values for the Mesozoic. With reference to these curves, the observed inclination of $29^{\circ} \pm 14^{\circ}$ corresponds to either a Middle Jurassic to Early Cretaceous age (170-90 Ma) or a Carboniferous through middle Triassic age. The younger paleomagnetic age corresponds well with the younger strontium time window. However, the strontium data limit the older paleomagnetic time range to only a portion of the Permian.

Magnetic polarities can be used to further restrict the possible age of the dolomite. The expected inclinations for the Permian are positive because Site 536 was south of the equator in the Permian and because most, if not all, of the Permian was a period of reverse polarity. During the Jurassic-Cretaceous interval, the magnetic polarity changed frequently. Distinguishing between the two possible ages can only be achieved if the dolomites have either reverse or mixed polarities, both being indicative of the younger age. If all inclinations are positive, either age is possible because the entire dolomite section (23 m) may represent a time span sufficiently short, (e.g., $1 \mathrm{Ma}$ ) for it to fall entirely within one polarity zone of the Jurassic-Cretaceous interval.

Inspection of Table 1 reveals three stratigraphically adjacent samples for which Component 2 has a negative inclination, defining an 8-m section (sub-bottom depth 186.47 to $194.17 \mathrm{~m}$ ) of reverse polarity. One other sample indicates a second reverse horizon, but without addi- 

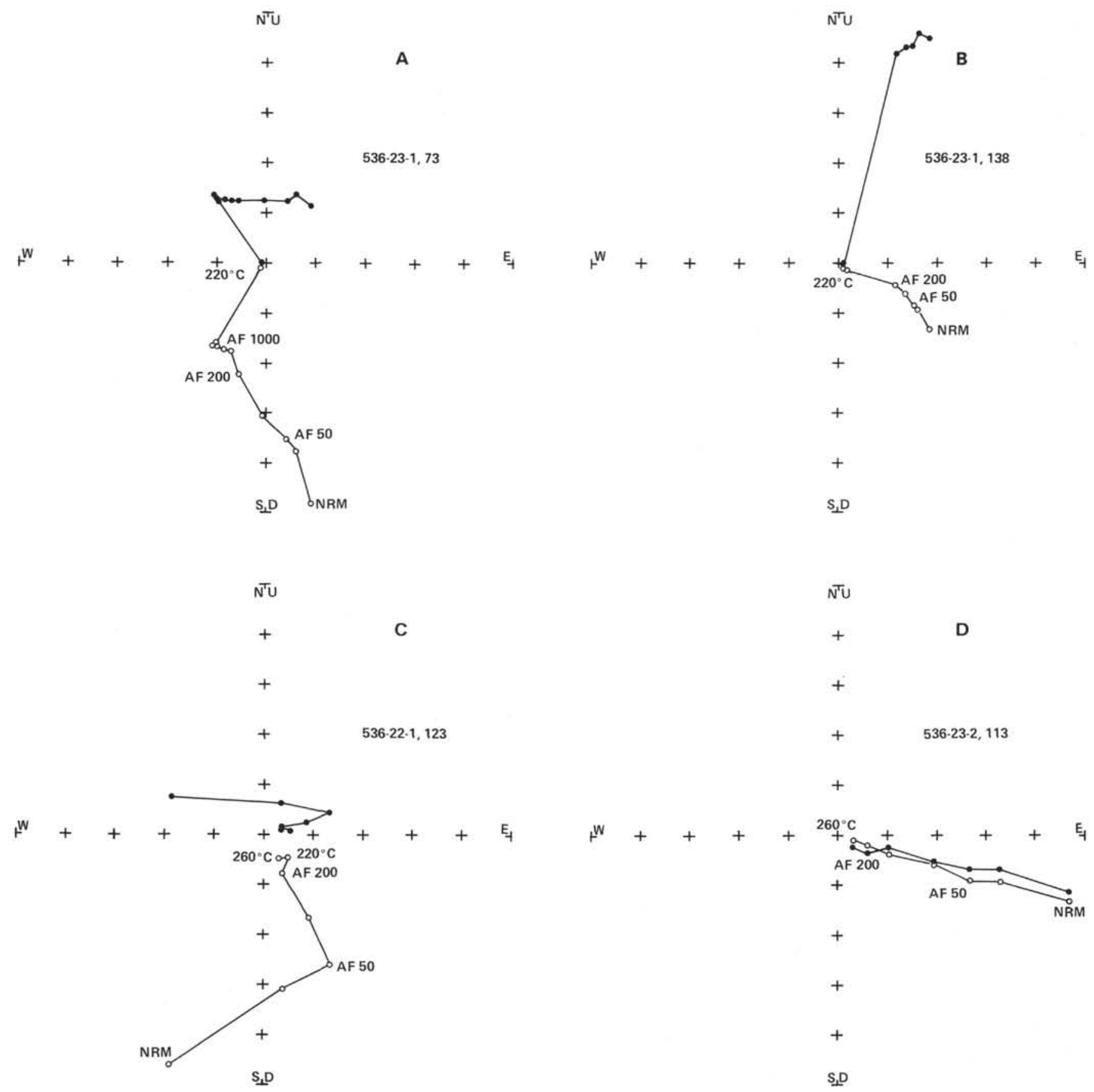

Figure 2. Exemplary orthogonal vector diagrams. Sample numbers are expressed as hole-core-section, depth in section in $\mathrm{cm}$. Closed circles represent north versus east component; open circles indicate up versus east component. NRM is natural remanent magnetization. A. Typical example described in the text: a single vector subtracted by alternating fields (AF) from 25 to $300 \mathrm{Oe}$; a stable direction from 300 to 1000 Oe; and then a sudden drop to negligible intensity upon heating to $220^{\circ} \mathrm{C}$. B. Similar to A, but only demagnetized to 200 Oe before being heated. C. A deviation from the general case in that the soft magnetization is subtracted up to $50 \mathrm{Oe}$, rather than $25 \mathrm{Oe}$. Also, there is no significant drop in intensity upon heating. D. The only sample to display just one component of magnetization.

tional sampling, the possibility of sample inversion cannot be ruled out. The occurrence of reversals in the dolomite section argues in favor of the Middle Jurassic to Early Cretaceous age.

\section{CONCLUSIONS}

The combined magnetic and strontium data suggest that the dolomite at Site 536 is of Middle Jurassic to
Early Cretaceous age. This interpretation could change should any of the assumptions on which it was based prove incorrect. These include: (1) that the strontium in the dolomite was incorporated from seawater at the time of deposition; (2) that Site 536 was in its present position relative to North America when the dolomite was deposited; and (3) that no reversals occurred during the Permian time window. The final assumption is subject 

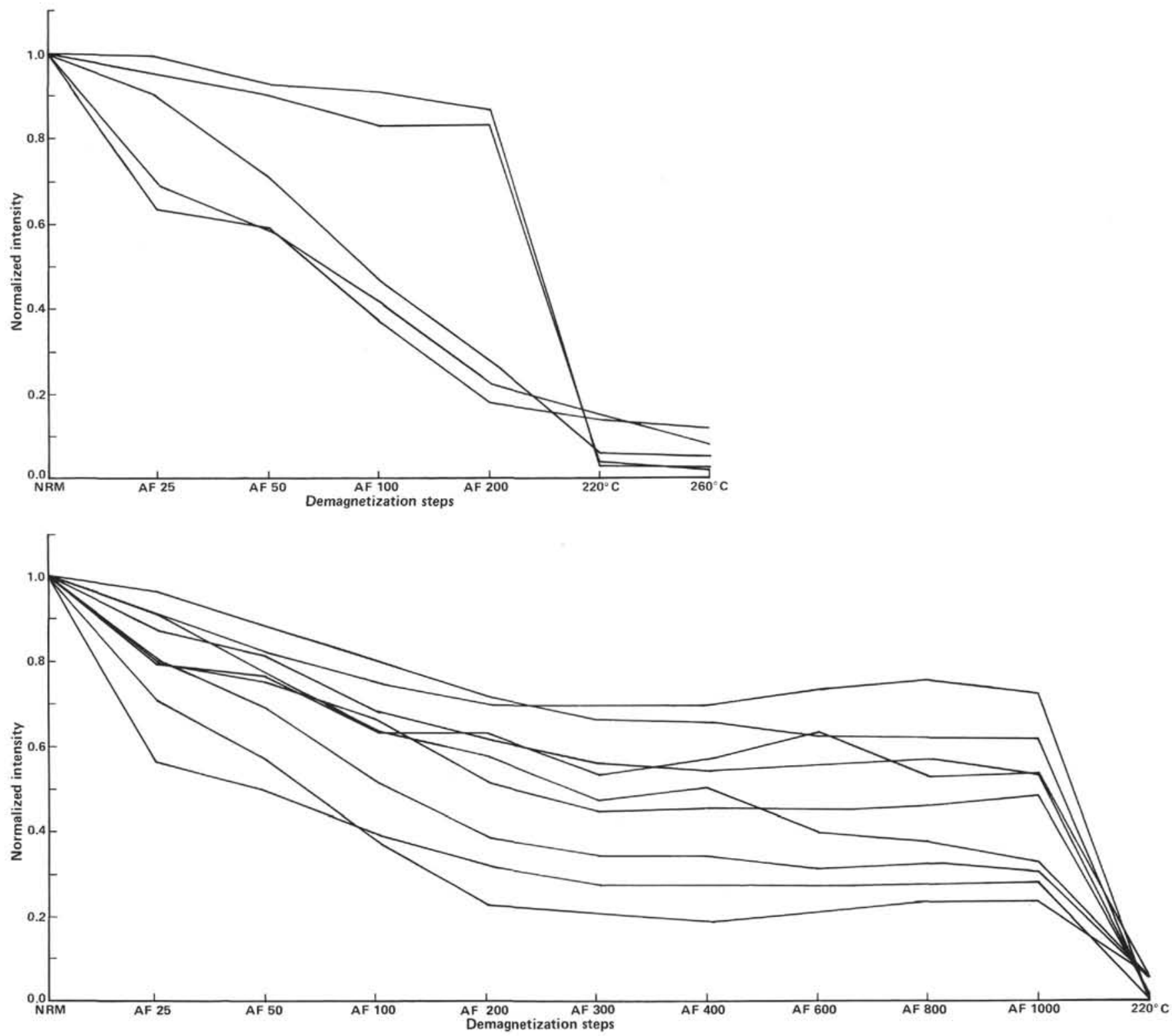

Figure 3. Normalized intensity as a function of demagnetization step for the two procedures. Most samples were fairly stable to alternating field (AF) demagnetization, especially above $200 \mathrm{Oe}$, but experienced a dramatic decrease in intensity upon low temperature thermal demagnetization. NRM is natural remanent magnetization.

to question because the late Permian has not been studied in sufficient detail to totally preclude short reversals.

\section{ACKNOWLEDGMENTS}

Dr. Robert Halley, a Leg 77 scientist from the U.S. Geological Survey, was instrumental in obtaining the ${ }^{87} \mathrm{Sr} /{ }^{86} \mathrm{Sr}$ data from the Mobil Field Research Laboratory. We greatly appreciate the review of the manuscript by Dr. Richard B. Koepnick, Mobil Research and Development Corporation, who also discussed the isotopic data with us extensively. This work was supported by the University of Texas at Austin and constitutes Institute for Geophysics Contribution No. 567.

\section{REFERENCES}

Burke, W. H., Denison, R. E., Hetherington, E. A., Koepnick, R. B., Nelson, H. F., and Otto, J. B., 1982. Variation of seawater ${ }^{87} \mathrm{Sr} /$ ${ }^{86} \mathrm{Sr}$ throughout Phanerozoic time. Geology, 10:516-519.

Harrison, C. G. A., and Lindh, T., 1982. A polar wandering curve for North American during Mesozoic and Cenozoic, J. Geophys. Res., 87:1903-1920.

Irving, E., 1979. Paleopoles and paleolatitudes of North America and speculations about displaced terrains. Can. J. Earth Sci., 16: 669-694.

Date of Initial Receipt: January 17, 1983

Date of Acceptance: November 1, 1983 

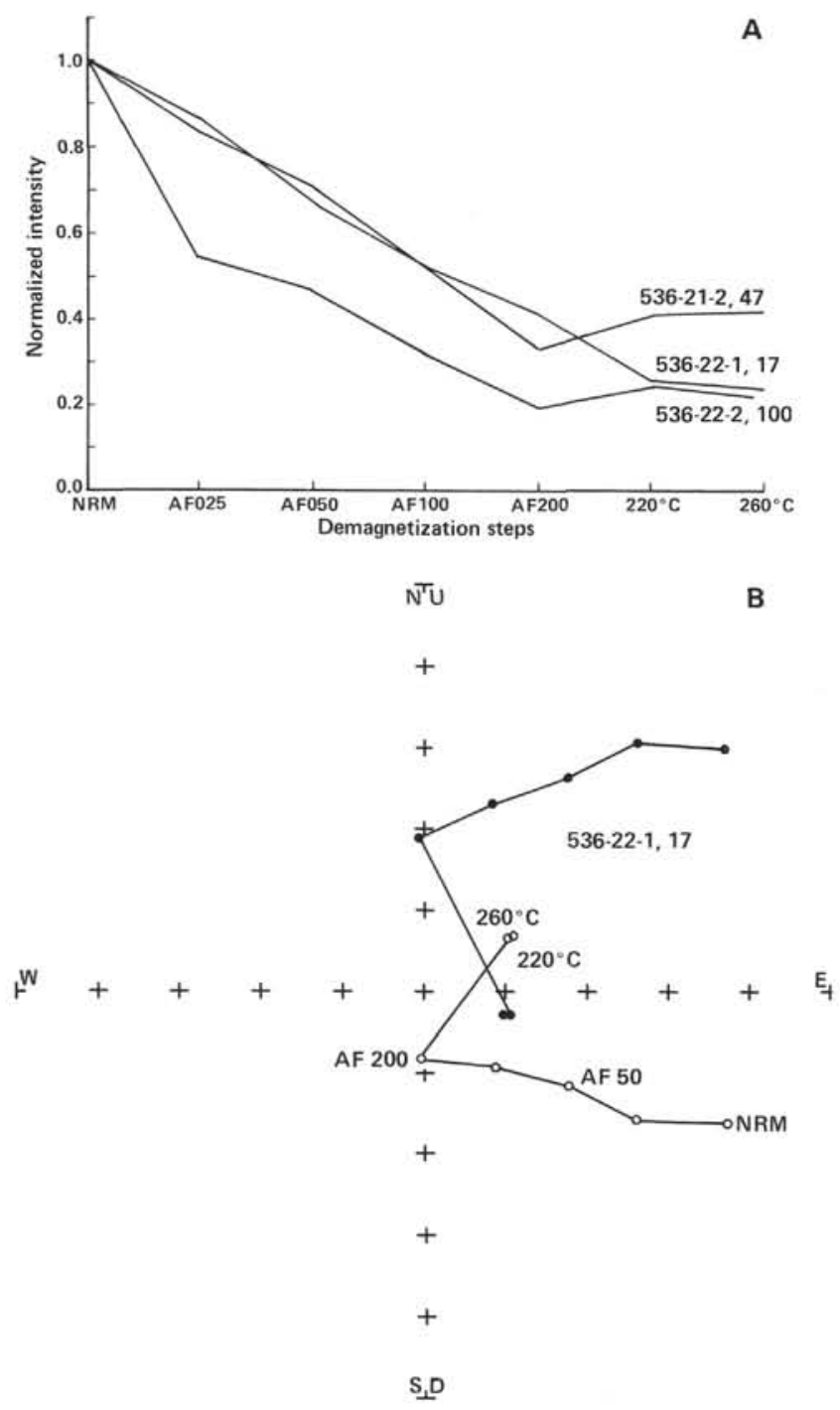

Figure 4. A. Normalized intensity as a function of alternating field (AF) demagnetization step for the three samples with a thermally stable component. NRM is natural remanent magnetization. Sample numbers expressed as in Figure 2. B. Orthogonal vector diagram of one of these samples shows the significant change in direction upon heating.
Table 1. Inclination of the two main components of magnetization of the Hole 536 dolomite.

\begin{tabular}{cccc}
\hline $\begin{array}{c}\text { Sample } \\
\text { (core-section, cm } \\
\text { from top of section) }\end{array}$ & $\begin{array}{c}\text { Sub-bottom } \\
\text { depth } \\
(\mathrm{m})\end{array}$ & Component 1 & Component 2 \\
\hline $21-1,13$ & 184.63 & 30.9 & 45.0 \\
1,109 & 185.59 & 50.1 & 17.2 \\
2,47 & 186.47 & - & -16.5 \\
2,92 & 186.92 & 52.1 & -3.2 \\
$22-1,17$ & 194.17 & 14.5 & -31.5 \\
1,65 & 194.65 & 38.3 & 38.5 \\
1,123 & 195.23 & 60.9 & 53.6 \\
2,51 & 196.01 & 63.7 & 19.3 \\
2,100 & 196.50 & - & -44.0 \\
3,28 & 197.28 & -11.4 & 26.2 \\
$23-1,10$ & 203.60 & 33.2 & 45.3 \\
1,73 & 204.23 & 53.8 & 46.4 \\
1,138 & 204.88 & 36.7 & 6.0 \\
2,35 & 205.35 & 16.0 & 30.9 \\
2,113 & 206.13 & 15.5 & 15.5 \\
3,3 & 206.53 & 31.2 & 23.2 \\
3,74 & 207.24 & 66.8 & 34.9 \\
3,133 & 207.83 & 79.2 & 25.6 \\
3,143 & 207.93 & 31.1 & 29.6 \\
& Mean & $40.3 \pm 19.8$ & $29.1 \pm 13.8$ \\
& & $\mathrm{~N}=17$ & $\mathrm{~N}=19$ \\
\hline
\end{tabular}
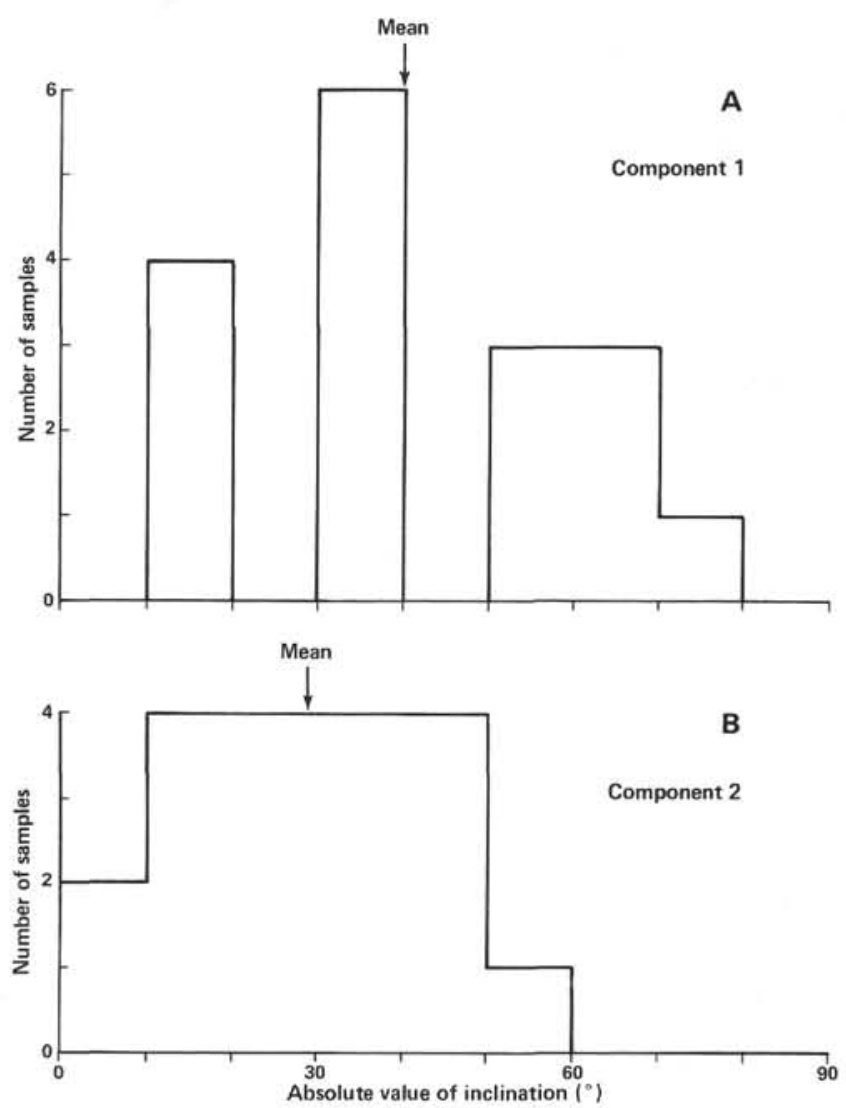

Figure 5. Distribution of absolute values of inclination for the two main components of magnetization. 
Table 2. ${ }^{87} \mathrm{Sr} /{ }^{86} \mathrm{Sr}$ ratios for dolomites from Hole 536.

\begin{tabular}{cc}
\hline $\begin{array}{c}\text { Sample } \\
\text { (core-section, cm } \\
\text { from top of section) }\end{array}$ & ${ }^{87} \mathrm{Sr} / 86 \mathrm{Sr}$ \\
\hline $21-1,27-30$ & $0.70701 \pm 0.00002$ \\
$22-2,53-56$ & $0.70712 \pm 0.00002$ \\
Duplicate & $0.70715 \pm 0.00003$ \\
$23-2,44-47$ & $0.70746 \pm 0.00002$ \\
$23-2,73-76$ & $0.70690 \pm 0.00005$ \\
\hline
\end{tabular}

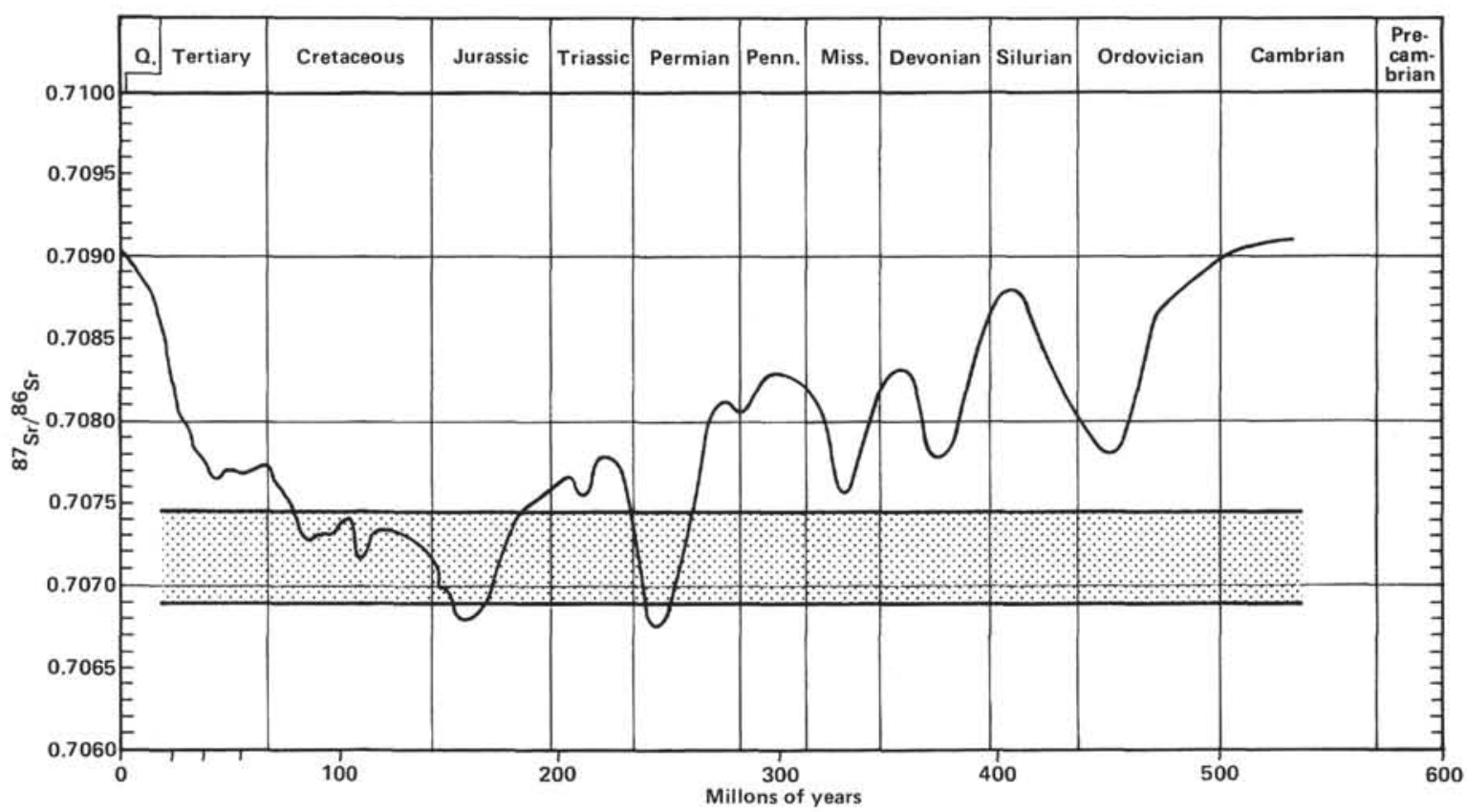

Figure 6. Range of ${ }^{87} \mathrm{Sr} /{ }^{86} \mathrm{Sr}$ ratios for four dolomite samples from Site 536 plotted on ${ }^{87} \mathrm{Sr} /{ }^{86} \mathrm{Sr}$ graph for the Phanerozoic (after Burke et al., 1982). The low ratios for the dolomite restrict its age to either Permian or Middle Jurassic to Late Cretaceous. 